\title{
Effect of fatigue testing on the properties of Glass-Epoxy composites using the acoustic tool
}

\author{
Younès Menail ${ }^{1, *}$, Abderrahim El Mahi ${ }^{2}$, Bachir Redjel $^{3}$, Rachid Berbaoui ${ }^{2}$ and Mustapha \\ Assarar $^{4}$ \\ ${ }^{1}$ LR3MI, Université Badji Mokhtar, Sidi Ammar, BP 12, Annaba, Algérie \\ ${ }^{2}$ LAUM, UMR CNRS 6613, Université du Maine, av. O. Messiaen, 72085 Le Mans, France \\ ${ }^{3}$ Laboratoire de Génie civil, Université d'Annaba, Algérie \\ ${ }^{4}$ Université de Reims Champagne Ardenne, LISM, EA 4695, IUT de Troyes, 9 rue de Québec, 10026 \\ Troyes Cedex, France
}

\begin{abstract}
This study presents the experimental results of the influence of mechanical fatigue on composite material. The plates of Glass fiber with SR 1500 epoxy resin with SD 2505 composite were realized by vacuum molding. Experimental tests were carried out on a standard hydraulic machine INSTRON 8516. The machine is interfaced with a dedicated computer for controlling and data acquisition. The fatigue tests were performed using sinusoidal type of waveform at a displacement control with frequency of $10 \mathrm{~Hz}$. The evolution of Young's modulus and strain based on fatigue gives us an idea about the resistance of the material. Degradation of mechanical properties was observed, and the results have showed that the Young's modulus of plates undergo only minor changes. In fact, the residual stiffness and residual strength decrease when the cycle number of fatigue increase (100 to 50000 cycles), indicating that the studied composites have experienced some forms of mechanical damage. The mechanical tests were backed by Acoustic Emission Monitoring (AEM) during the load cycle, in order to understand the nature of the failure process in the composites such as fiber breakage, matrix crazing, matrix debonding and delamination etc.
\end{abstract}

\section{Introduction}

The XXI century is a century of research, innovation and competition. This is the century of new materials. And polymer matrix composites are at the top of the list. Their characteristics, modes of varieties and their costs open all fields, including automotive, aviation, aerospace, shipbuilding, oil industry, civil engineering and many other fields.

The choice of fibers and resins depends on several parameters such as Workplace [1-2], cost, features required, technical moldings, life, etc., because these materials must meet specific conditions. Research in this area is vast and varied and researchers are expected to

\footnotetext{
*Corresponding author: menailyounes43@gmail.com
} 
fully optimize the performance of these materials by simulations and practical research in situ.

These materials have invested among many other domains, petrochemical, whether on land or offshore. While the results of work in this area are not as numerous as in other areas, but the results show that the composite materials are required as key materials in the field of petrochemicals. They do not corrode and they have a very low coefficient of expansion compared to steel [3-4].

We want know if this material can be used in petrochemical, whether on earth and suffer significant temperature gradient or suffer substantial pressure for offshore use. [5] For this, we subject this material cyclic tensile fatigue then we submit to the effect of the wetland during well-defined periods.

To understand the phenomena experienced by this material, we used the acoustic tool to monitor different degradations that occur within these (matrix cracking, delamination, debonding and breakage of matrix and fibers) [6 - 10].

\section{Experimental procedure}

To carry out our work, we selected materials that have proven themselves in the market, and have made their molding with great care to have identical specimens, having the same characteristics.

\subsection{Plates}

To achieve our glass test plates E twill, we used a mixture of epoxy resin SR 1500 associated with $2505 \mathrm{SD}$ amine hardener and respected percentages recommended by the supplier Sicomin Composites France, Table 1. After contact molding, by said vacuum bag for 6 hours under a vacuum of 0.3 bar technique, we obtained parallelepipedal plates. What we placed in an oven at $80{ }^{\circ} \mathrm{C}$ for 8 hours for polymerization. The specimens are cut thereafter the recommended dimensions $(200 \times 20 \times 1) \mathrm{mm}$ using a diamond disc mounted on a chainsaw. The weight content of fiber materials is determined by calculation and verified by loss on ignition.

Table 1. Material

\begin{tabular}{|c|c|c|c|c|c|c|c|c|}
\hline Fibre & weaving & $\begin{array}{c}\text { density } \\
{[\mathrm{g} / \mathrm{m} 2]}\end{array}$ & $\begin{array}{c}\text { mass } \\
{[\%]}\end{array}$ & Resin & supplier & $\begin{array}{c}\text { Dimensio } \\
\text { ns [mm }]\end{array}$ & Layer & $\begin{array}{c}\text { weight } \\
{[\mathrm{g}]}\end{array}$ \\
\hline Glass E & twill & 300 & 65 & $\begin{array}{c}\text { SR } 1500 \\
\text { SD } 2505\end{array}$ & $\begin{array}{c}\text { Sicomin } \\
\text { France }\end{array}$ & $200 \times 20 \times 1$ & 4 & 7.2 \\
\hline
\end{tabular}

\subsection{Equipments}

Tensile tests were conducted on a universal hydraulic machine INSTRON model 8516, equipped with a load cell of $100 \mathrm{kN}$, the following standard ASTMC365-57, represented in Figure 1. Steering and data acquisition are done by computer, to record the evolution of the stress in function of the deformation. The tests are performed at room temperature. The machine is driven at constant speed through. This speed was determined after a series of preliminary tests, which helped set it to $1 \mathrm{~mm} / \mathrm{min}$ for all types of samples. The use of the same speed, regardless of the type of test, overcomes the viscoelastic effect of the resins, when comparing results from different tests. 
Monitoring and acoustic data acquisition, are in parallel with the mechanical tests, thanks to another computer connected to the test with three sensors placed longitudinally. Software processes the data for acoustic monitoring.

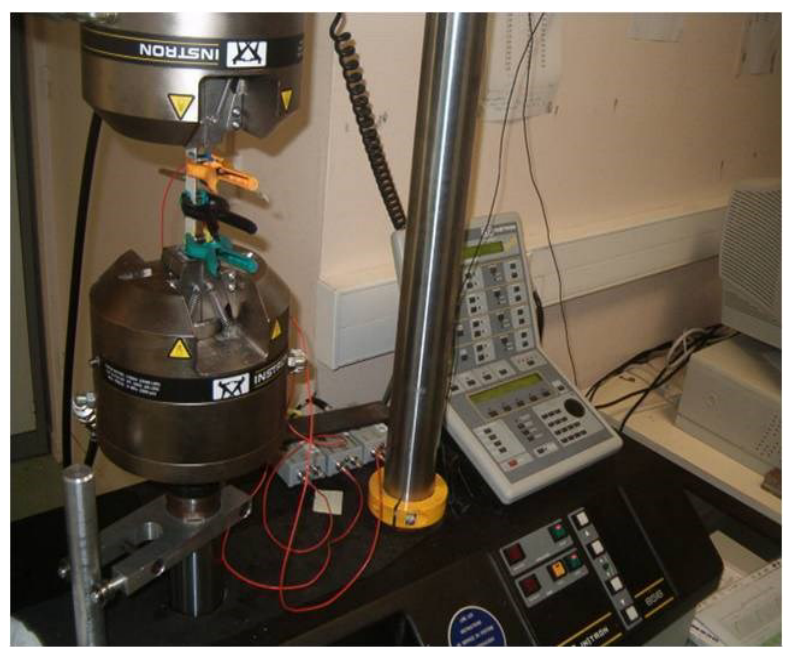

Fig. 1. Tensile machine and acoustic equipment

\subsection{Environment}

The various specimens were subjected to two different environments in this case, the ambient air and tap water Table 2. Series of test pieces subjected to the air ambient serves as reference. After fatigue, the specimens were immersed in the same time in different environments, at 100, 500 and $1000 \mathrm{~h}$, before undergoing final tensile loading until failure. The various pieces are subjected to the ambient laboratory temperature, which varies depending on the season $\left(15-25^{\circ} \mathrm{C}\right)$. After loading, they are placed in PET containers, undergoing both daylight and night light variations.

Table 2. Environment

\begin{tabular}{|l|l|l|l|l|l|l|l|l|}
\hline Fibre & weaving & $\begin{array}{l}\text { density } \\
{[\mathrm{g} / \mathrm{m} 2]}\end{array}$ & $\begin{array}{l}\text { mass } \\
{[\%]}\end{array}$ & Resin & supplier & $\begin{array}{l}\text { Dimensions } \\
{[\mathrm{mm}]}\end{array}$ & Layer & $\begin{array}{l}\text { weight } \\
{[\mathrm{g}]}\end{array}$ \\
\hline $\begin{array}{l}\text { Glass } \\
\text { E }\end{array}$ & twill & 300 & 65 & $\begin{array}{l}\text { SR } 1500 \\
\text { SD } 2505\end{array}$ & $\begin{array}{l}\text { Sicomin } \\
\text { France }\end{array}$ & $200 \times 20 \times 1$ & 4 & 7.2 \\
\hline
\end{tabular}

\subsection{Mechanical Testing}

To determine the impact of tap water on the composite epoxy-glass material, we conducted two sets of mechanical tensile tests, static tests and fatigue tests.

Static tests allow us to determine the stress $\sigma$ and the corresponding strain $\varepsilon$. These two parameters allow us to characterize the two materials.

\subsubsection{Static tests}

Three to five pieces of glass, as the case may undergo static tensile tests to determine both stress and strain parameters needed for testing fatigue. 


\subsubsection{Fatigue testing}

From the results of static tests, we opted for the optimal values of displacement and amplitude fatigue, to achieve the fatigue testing.

The experimental protocol was done as follows figure. 2:

- Loading of the specimen at a constant tensile rate $1 \mathrm{~mm} / \mathrm{mn}$ under controlled $50 \%$ displacement at break static displacement.

- Fatigue with a sine wave form, at a frequency of $10 \mathrm{~Hz}$ with an amplitude of $10 \%$ of the displacement at failure. In our case, we opted for a number of fatigue cycles 10000 cycles.

- Unloading the specimen after fatigue.

- Aging in tap water according to the case (and in the air for controls).

- And finally, a tensile strength with speed of movement of $1 \mathrm{~mm} / \mathrm{mn}$.

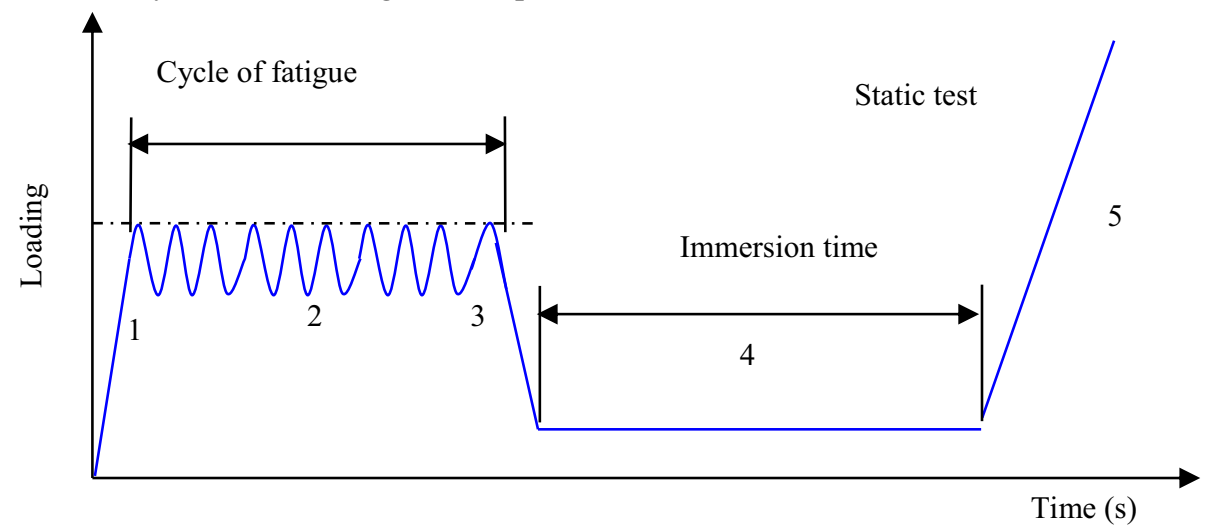

Fig.2. Experimental protocol

\subsection{Immersion}

Fatigues after specimens are immersed in tap water. A series of samples was left in the open air as a witness. The immersion times are of the order of 100, 500 and $1000 \mathrm{~h}$. Thereafter the specimens are removed from the water according to a program to be broken in tension, as for the static test.

\section{Results and discussion}

The results obtained in our research work is divided into two, the preliminary results of static tensile tests, which serve as a basis and the results of stress tests, the subject of our work.

\subsection{Static Tests}

The curves of static tests for glass-epoxy material are manifested by a proportional increase between stress and strain. They indicate brittle-type behavior of the materials, which is manifested by a substantially linear variation of the stress in function of the deformation. The tensile force causes a progressive matrix cracking, the weakest of the composite element. 
This cracking is followed by debonding and delamination, which further weaken the material. The effort is continuous, the material being weakened, the composite will sell quickly with a sudden drop in stress indicating fiber breakage and end of life of the material, Figure 3.

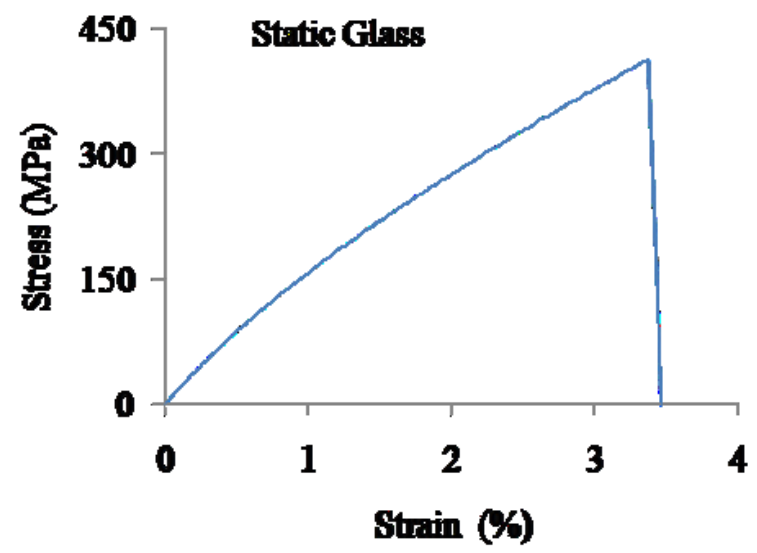

Fig.3. Stress-strain responses under tension loading GFRP

Three sensors connected to the plates allow us through specialized software to record and view live the effect of tensile stress on the materials. Consulted the literature does not accurately distinguish different ranges corresponding to different mechanisms of damage. De Groot and al. [11] Che and al [12], Kim and Lee [13] Karger-Kocsis and al. [14] Kotsikos and al. [15-16] and Benzeggagh and al. [17-18], all these authors and many others have classified the amplitudes into three or four groups, as appropriate, to involve the various failure modes of composite materials. They ranked the lowest to the highest, to associate the matrix cracking and delamination and debonding of those and finally fiber breakage. For we know that against degradation is gradually starting with the matrix cracking, followed by debonding, delamination at the fiber matrix interface, comes on and in parallel to complete delamination followed by fiber breakage. Each type of damage is characterized by its amplitude range. It should be noted that these overlap one another and on the other hand the various authors do not give the same amplitudes for the same damage [19-21].

We opted for the following average values:

- cracking of the matrix, amplitudes between 40 and $60 \mathrm{~dB}$,

- debonding and delamination amplitudes between 60 and $70 \mathrm{~dB}$,

- rupture of fibers amplitudes between 70 and $85 \mathrm{~dB}$ and more.

- the amplitude range between 0 and $40 \mathrm{~dB}$ is eliminated, since it corresponds to the noise generated by the machine, friction, background noise, etc..

These different amplitude ranges allow us to identify the different damage suffered composites during static and fatigue tests. The acoustic tool allows us to better visualize the degradation of materials and make a more accurate comparison.

The test results of the static tensile test show that the glass is broken after 230 seconds biasing (table 3. and figure.3.). During the first 50 seconds is that the matrix begins to crack under the effect of the traction, which represents less than $20 \%$ of the life of material. After this period, it is the different types of damage that occur until the final failure of the material. We can say that the damage is done gradually from the beginning to the end, starting with the cracking of the matrix followed by delamination and debonding, ending with fiber breakage. 
Table 3. Physical and Mechanical properties of GFRP and KFRP

\begin{tabular}{|c|c|c|c|c|c|}
\hline Fibre & $\begin{array}{l}\text { Speed } \\
{[\mathrm{m} / \mathrm{mn}]}\end{array}$ & $\begin{array}{l}\text { Maximal stress } \\
{[\mathrm{MPa}]}\end{array}$ & $\begin{array}{l}\text { Maximal } \\
\text { strain [\%] }\end{array}$ & $\begin{array}{l}\text { Longitudinal } \\
\text { module [GPa] }\end{array}$ & $\begin{array}{l}\text { Transversal } \\
\text { Module [GPa] }\end{array}$ \\
\hline Glass & 1 & 380 & 3.5 & 16 & 16 \\
\hline
\end{tabular}

\subsection{Testing of tensile fatigue}

The tensile fatigue tests are made according to the protocol mentioned above, Table 4. Specimens undergo a load equal to $50 \%$ of the displacement at break static at a frequency of $10 \mathrm{~Hz}$ and an amplitude of $10 \%$ of the displacement at failure. We opted for a stress fatigue of the order of 10,000 cycles. Fatigue manifests itself as a matrix cracking, throughout the operation. Delamination and debonding are very low and the fiber breakage is very rare. Work Talreja [22] taken by Muc [23] explain the evolution of the damage in three stages: the collapse of the matrix, delamination and fiber breakage. We stopped fatigue testing to 10,000 cycles before the final break, immersing the samples in different environments.

Table 4. Experimental data

\begin{tabular}{|c|c|c|c|c|c|c|c|c|}
\hline 竞 & 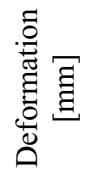 & 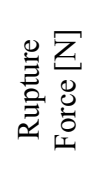 & 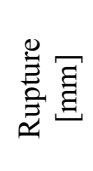 & 总军 & 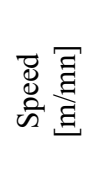 & 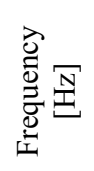 & 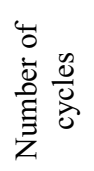 & 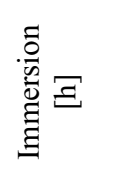 \\
\hline Glass & 3.54 & 8000 & 1.76 & 0.35 & 1 & 10 & 10000 & $\begin{array}{l}100,500 \\
1000\end{array}$ \\
\hline
\end{tabular}

\subsection{Effects of Aging}

Fatigue after 10000 cycles, the specimens was immersed in tap water, as appropriate, for 100,500 and 1000 hours, to undergo the same aging water. Whereupon, they undergo static tension until failure.

This choice aging times is based on a literature study to clearly identify the behavior of composite materials in wet conditions. Damage by cracking due to significant osmotic water uptake has been identified beyond 120 hours of aging. These results confirm the state of damage of the material. [24] At $20^{\circ} \mathrm{C}$, the samples quickly reach equilibrium (35 days), $0.35 \%$ absorption and a model Frick can adequately describe the absorption [25] kinetics. At a temperature of $23^{\circ} \mathrm{C}$, the interactions between moisture and fatigue damage can only be done locally, after capillary moisture in the crack tip [26]. Up to $50^{\circ} \mathrm{C}$, the loss of properties due to plasticization of reversible phenomena of the matrix [27]. Different studies which we referred we have shown that osmotic origin of degradation of composite materials has been confirmed by preliminary tests in seawater and distilled water [28]. The attack of the resin in the laminate occurs between two folds and led to a decline of the most important mechanical properties [29].

At an exhibition in wet, it is known that the glass-epoxy composites can undergo three main types of damage:

- Reversible lamination process of the matrix resulting from water sorption in polyepoxide network, 
- Macroscopic damage (matrix cracking, fiber debonding / matrix .....), either from the chemical degradation of the polyepoxide network or stress induced by differential swelling water sorption,

- Chemical attack of the reinforcement in the case of glass fibers, which results in a loss of tensile strength. This particular fiber degradation allows the creation of surface defects by heavily dependent on physico-chemical characteristics of the surrounding environment [30-33] ion exchange mechanism.

The results, given in Figure 4 are compared among themselves to highlight the effect of aging on epoxy-glass composite. For fatigue damage is brittle type for the series of samples tested. First, a quasi-linear variation of the stress in function of the deformation, then a sudden drop in the latter. This drop is due to fiber breakage, causing the total failure of the specimen.

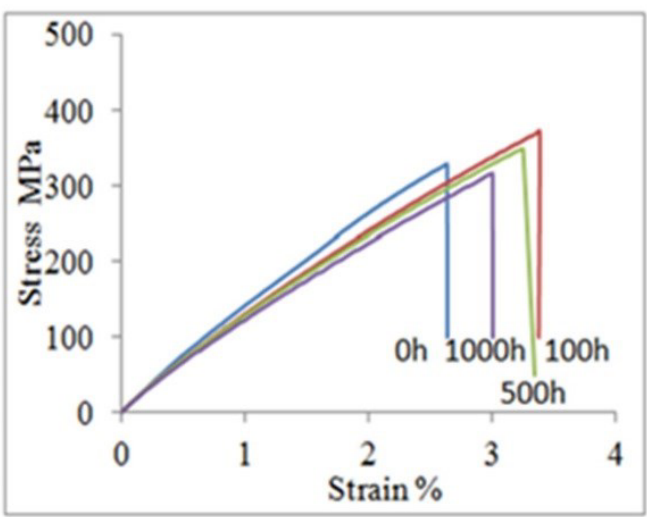

Fig 4. Evolution mechanical behaviour according to the immersion duration and fatigue test

A comparative study of the effect of fatigue and aging tap water allows us to make the following observation figure 4:

- For epoxy-glass test plates, the values of stress and strain are higher than that of the control samples remained in the open air.

In general, all the samples, regardless of their nature, experience a larger than those of the control specimens elongation. This is explained by capillary diffusion of moisture in the crack in the gaps left by fatigue by creating a differential swelling induced by water sorption. This gives the matrix lamination, giving it certain elasticity, it does not naturally.

The $\sigma / \varepsilon$ ratio of stress to strain given by the tangent $\alpha$, gives us an idea of material degradation due to fatigue and aging, Tables 5 and Figure 5 shows us that effect, indicated by a sharp drop of the material characteristics. We conclude that fatigue followed by aging alters the characteristics of the glass-epoxy specimens.

Table 5. Glass's stress and strain

\begin{tabular}{|l|l|l|}
\hline \multicolumn{3}{|c|}{ Glass Tap water (gtw) 10000 cycles } \\
\hline$\sigma[\mathrm{MPa}]$ & $\varepsilon[\%]$ & $\sigma / \varepsilon_{\mathrm{gtw}}$ \\
\hline$\sigma_{\mathrm{gtw} 0}=328,06$ & $\varepsilon_{\mathrm{gtw} 0}=2,64$ & 124.26 \\
\hline$\sigma_{\mathrm{gtw} 100}=373,43$ & $\varepsilon_{\mathrm{gtw} 100}=3,38$ & 110.48 \\
\hline$\sigma_{\mathrm{gtw} 500}=347,59$ & $\varepsilon_{\mathrm{gtw} 500}=3,24$ & 107.28 \\
\hline$\sigma_{\mathrm{gtw} 1000}=315,58$ & $\varepsilon_{\mathrm{gtw} 1000}=3,00$ & 105.19 \\
\hline
\end{tabular}




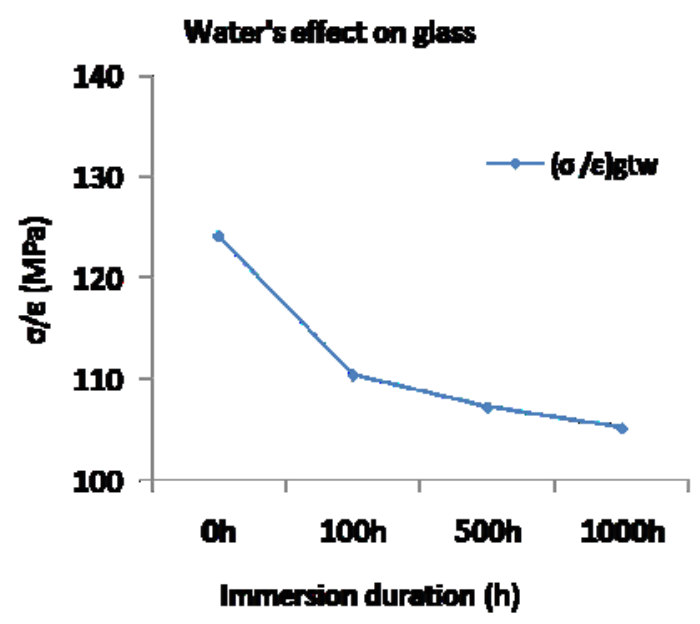

Fig. 5. Water's effect

The foregoing results show that the test pieces of glass-epoxy subjected to progressive aging after tensile fatigue undergo a gradual loss of resistance as a function of the immersion time.

For acoustic monitoring, we opted for a fatigue life of 10,000 cycles and immersion time of $100 \mathrm{~h}$, figure 6.

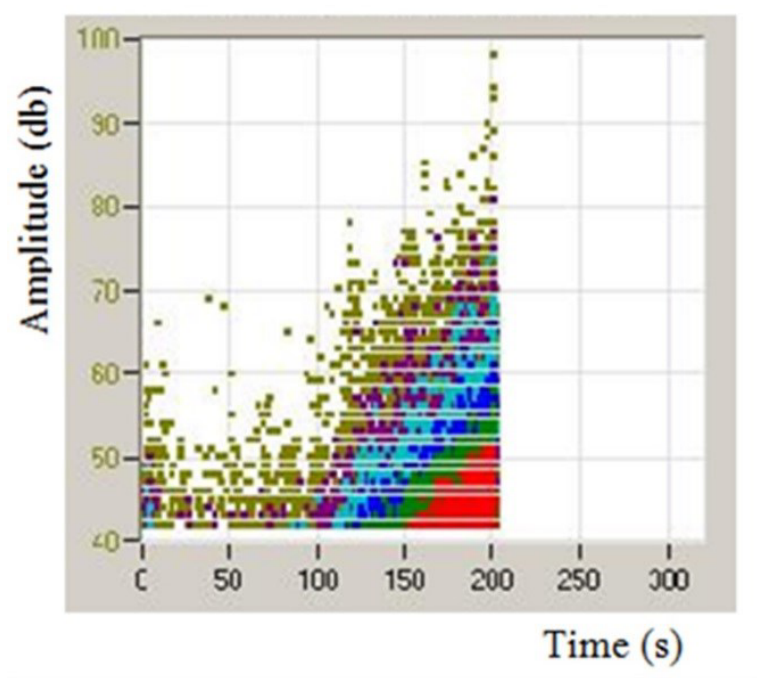

Fig. 6. Fatigue 10000 cycles and immersion $100 \mathrm{~h}$

The glass plates exhibit a matrix cracking for 100 seconds, which correspond to $50 \%$ of the life of the material. We find that aging tap water gives the resin plates a greater elongation. The acoustic monitoring allows us to better visualize the different mechanical phenomena experienced by different materials. These results allow us to distinguish the various ranges of different damage. They also allow us to see that the same fatigue and even aging does not have the same impact on the epoxy resin, for glass. This may be due to the binding resin fiber which is not the same for materials. 


\section{Conclusion}

This study aimed at investigating the influence of water ageing after fatigue on the mechanical proprieties of glass-fibre reinforced epoxy composite. The test specimens were subjected to fatigue for various numbers of 10000 cycles and aged in tap water for varying lengths of time $(100,500$ and $1000 \mathrm{~h})$ under acoustic control. Then the composite specimens were tested in tension in order to determine the evolutions of the strength and stiffness under local interactions of the humidity and fatigue.

From this investigating, the following conclusions can be drawn:

-The tensile mechanical proprieties are clearly affected by water ageing and fatigue, both on the shape of the stress-strain curves and on the properties' values.

- The specimens subjected to the tap water are more fragile than those which were preserved in the air.

- The residual stiffness and residual strength decrease when immersion time increases, indicating that the material has experienced some forms of mechanical damage and irreversible chemical degradation. The decrease in stiffness and strength are explained by the degradation of fiber / matrix interfacial by water absorption and the swelling of the matrix.

\section{References}

1. A.M. Visco, N. Campo, P. Cianciafara. Composites: Part A 42, 123 (2011)

2. K. Imielinska, L. Guillaumat. Compos Sci Technol 64, 2271-2278 (2004)

3. E. Poodts, G. Minak, A. Zucchelli. Composite Structures 97, 222-230 (2013)

4. N. Godin, S. Huguet, R. Gaertner. Composite Structures 72, 79-85 (2006)

5. P. Odru, B. Dewimille, F. Grosjean, and M. Huvey. Journées Scientifiques et Techniques AMAC (1996)

6. K. Ono. Acoustic emission encyclopedia of acoustics (New York: Wiley, 1997)

7. A.G. Beattie. J Acoustic Emiss 1/2, 95-128 (1983)

8. A. Nielsen. The Danish Welding Institute Publication, 80, 15 (1980)

9. A. Marec, J-H. Thomas, R. El Guerjouma. Mech Syst Signal Proc, 22, 1441-1464 (2008)

10. H. Gu, S. Hongxia. Mater Des, 29, 262-4 (2008)

11. P. J. De Groot, P. A. M. Wijnen, and R. B. F Janssen. Composites Science and Technology, 55, 405-412 (1995)

12. O. Chen, P. Karandikar, N. Takeda, and T. Kishi. Nondestructive Testing and Evaluation, 8-9, 869-878 (1992)

13. S-T. Kim, and Y. T. Lee. Materials Science and Engineering, A 234-236, 322-326 (1997)

14. J. Karger-Kocsis, T. Harmia and T. Czigany. Composites Science and Technology, 54, 287-298 (1995)

15. G. Kotsikos, J.T. Evans, A.G. Gibson, and J.M. Hale. Polym Compo, 20 (5), 689-696 (1999)

16. G. Kotsikos, J.T. Evans, A.G. Gibson, and J.M. Hale. Composites-part A 31, 969-977 (2000)

17. M.-L. Benzeggagh, S. Barre, B. Echalier, and R. Jacquemet. AMAC Journées Nationales Composites, Paris, 8, 703-714 (1992)

18. S. Barre, M.-L. Benzeggagh. Composites Science and Technology, 52, 369-376 (1994)

19. S. Huguet, N. R. Godin Gaertner, L.Salmon and D.Villard. Compos Sci Technol, 62, 1433-1444 (2002)

20. H. Nechad. Thèse à l'Institut National des Sciences Appliquées de Lyon (2004)

21. M. Bentahar. Thèse de L'Institut National des Sciences Appliquées de Lyon (2005)

22. R. Talreja. Fatigue of composite materials: Analysis, Testing and Design, Siminar (Technomic publishing Co Inc., Lancaster, Basel, Switzerland, 1990)

23. A. Muc. Computers and Stuctures, 76, 211-218 (2000)

24. M.P. Foulc, A. Bergeret, P. Ienny, L. Ferry and A. Crespy. Matériaux (2002)

25. F. Dal Maso, B. Dewille , F. Grojean, M. Huvey, J. Martin et L. Montabord. Annale des composites, AMAC, France, 27-37 (1996) 
26. S. Popineau, C. Rondeau-Mouro, C. Sulpice-Gaillet, and M. Shanahan. Polymer, 46, 10733$10740(2005)$

27. A. Chateauminois, B. Chabert, J.P. Soulier, and L.Vincent. Annale des composites, AMAC, France, 823-832 (1990)

28. P. Castaing, and L. Lemoine. Polymer Composites, 16, 5, 349-356 (1995)

29. Ph. Castaing, N. Tsouvalis, and L. Lemoine. IFREMER, Actes de colloques, 15, 34 (1992)

30. E. Vautier, J.C. Abry, T. Bailliez, and Chateauminois. Journées Scientifiques et Techniques $A M A C$, France, 49-58 (1996)

31. A-HI. Mourad, AM. Beckry Mohamed, T. El-Maaddawy. Appl Compos Mater, 17, 557-573 (2010)

32. A. Kootsooks, and AP. Mouritz. Compos Sci Technol, 64, 1503-1511 (2004)

33. H. Gu. Mater Des, 30, 1337-1340 (2009) 